\title{
Serum C-reactive protein levels in pre-dialysis chronic kidney disease patients in southern Nigeria
}

\author{
Oluseyi A. Adejumo ${ }^{1}$, Enajite I. Okaka ${ }^{2}$, Chimezie G. Okwuonu ${ }^{3}$, Ikponmwosa O. Iyawe ${ }^{2}$ and \\ Oluwole O. Odujoko ${ }^{3}$
}

${ }^{1}$ Department of Internal Medicine, Kidney Care Centre, Ondo, Ondo State, Nigeria. ${ }^{2}$ Department of Internal Medicine, University of Benin Teaching Hospital, Benin, Benin City, Edo State, Nigeria ${ }^{3}$ Department of Internal Medicine, Federal Medical Centre, Umuahia, Abia State, Nigeria ${ }^{4}$ Department of Pathology, Ladoke Akintola University of Technology, Ogbomoso, Oyo State, Nigeria

DOI: http://dx.doi.org/10.4314/gmj.v50i1.5

Corresponding Author: Dr Oluseyi A. Adejumo

Email: ceeward2010@yahoo.com

Conflict of interest: None declared

\section{SUMMARY}

Background: Cardiovascular disease is the major cause of hospitalization and mortality in chronic kidney disease (CKD). C-reactive protein (CRP) is a marker of cardiovascular disease and predictor of mortality in CKD patients. CKD patients with elevated CRP should be identified early with institution of measures to treat cardiovascular risk factors in order to reduce attendant mortality.

Aims: Determination of serum CRP levels in CKD patients and associated factors.

Methods: This was a case-control study involving 80 consecutive CKD patients and 40 control subjects without CKD. Data obtained from participants included demographics, body mass index (BMI), and aetiology of CKD. Serum CRP levels, albumin, creatinine and lipid profile were determined. Cases and controls were compared. P values $<0.05$ were taken as significant

Results: The mean age of the CKD subjects was $49.09 \pm 16.85$ years. The median CRP value was significantly higher in the CKD group compared to controls $(\mathrm{p}=<0.001)$. Low, average and high cardiovascular event risk according to CRP values were present in 51(63.8\%), 13(16.2\%) and 16(20\%) of the CKD patients respectively. Cardiovascular event risk was significantly higher in CKD subjects $(p=<0.001)$. Serum creatinine, BMI, triglyceride and atherogenic index of plasma correlated positively with CRP. Estimated glomerular filtration rate (eGFR), high density lipoprotein-cholesterol and albumin correlated negatively with CRP. Elevated serum CRP was significantly predicted by low eGFR and high BMI on multivariate analysis.

Conclusion: Chronic kidney disease patients have increased cardiovascular event risk. Interventions aimed at reducing weight and treating dyslipidaemia should be instituted early in order to reduce this risk.

Keywords: C-reactive protein, chronic kidney disease, Nigeria

\section{INTRODUCTION}

Cardiovascular disease (CVD) accounts for about $40 \%$ of hospitalization and $50 \%$ of mortality in CKD patients at all stages. ${ }^{1,2}$ In end stage renal disease (ESRD) patients, CVD mortality rate is about 10-20 times higher than the general population. ${ }^{3}$ The process of CVD most likely started in early stages of CKD considering its severity at commencement of renal replacement therapy (RRT).

Elevated serum C-reactive protein (CRP) levels have been shown to be linked with the development of atherosclerosis in CKD patients. ${ }^{5}$ C-reactive protein is an acute phase reactant that belongs to the protein family known as pentraxin.
It is synthesized by the liver in response to cytokines such as interleukin-1, interleukin-6, tumour necrosis factor-alpha released from macrophages and adipocytes.

Chronic kidney disease is a chronic inflammatory state caused by both patient and dialysis related factors. These factors include the uremic milieu, infection, oxidative stress, co-morbidities, obesity, genetic or immunologic factors, exposure to dialyzer membrane and dialysate in those on dialysis. ${ }^{6}$

The levels of inflammatory markers like fibrinogen, homocysteine, CRP are high in CKD patients with coronary heart disease (CHD). ${ }^{7}$ 
Consequences of chronic inflammation in CKD patients include malnutrition, anaemia, hypo-responsiveness to erythropoietin, CVD and increased mortality. ${ }^{8-10}$

Amuk et al reported that CRP and endothelial function could provide complementary prognostic information regarding future cardiovascular disorders in renal patients. ${ }^{11}$ Earlier reports have also established CRP as a valuable predictor of future cardiovascular events in CKD. ${ }^{12,13}$

C-reactive protein levels of $<1 \mathrm{mg} / \mathrm{L}, 1$ to $3 \mathrm{mg} / \mathrm{L}$, and $>3 \mathrm{mg} / \mathrm{L}$ correspond to low, moderate, and high-risk groups for future cardiovascular events. ${ }^{14}$ Therefore, CKD patients with a high cardiovascular event risk can be closely monitored and aggressive cardiovascular risk factor modification instituted before they develop cardiovascular disease.

The aim of this study was to determine serum levels of CRP and its relationship with other parameters in CKD patients attending a tertiary hospital in southern Nigeria.

\section{METHODS}

\section{Study Location}

The Renal Unit, Department of Internal Medicine of University of Benin Teaching Hospital receives referral from within and outside the state of location. An average of 12 newly diagnosed CKD patients are seen in the unit monthly while about same number commence maintenance haemodialysis monthly.

\section{Study Design}

This was a case control study spanning one year period (September 2012 to August 2013) that involved 80 consecutive pre-dialysis CKD patients and 40 age matched controls with normal renal function. Sample size was derived using the Fleiss formula ${ }^{15}$ for case-control study with the following information:

Confidence interval $=95 \%$, power of study $=80 \%$, ratio of cases to control of $2: 1$, percentage of control exposed: $28{ }^{16}$ and percentage of cases exposed: $62 .{ }^{17}$ This formula gave a minimum sample size of 50 for cases and 25 for control.

Inclusion criteria for CKD subjects were: adults aged $\geq$ 18 years, patients with CKD stages $1-5$ yet to commence dialysis and those who gave consent to participate in the study. CKD patients with positive HIV, hepatitis B or hepatitis C status, those with chronic liver disease, those with active infection and those on statins or who smoke were excluded from the study. Inclusion criteria for control subjects were adults aged $\geq 18$ years with normal renal function, absence of chronic liver disease, negative hepatitis $\mathrm{B}$, hepatitis $\mathrm{C}$ and HIV status, not being on lipid lowering medications and who do not smoke.

Questionnaires were administered to the study subjects by the researchers to obtain demographic information such as age, gender and clinical history such as history of renal symptoms, common aetiologies such as hypertension, diabetes mellitus, retroviral disease, haemoglobinopathy, obstructive uropathy, connective tissue disease and previous or family history of renal disease. Study subjects were physically examined and their blood pressure measurements were taken. Blood pressure of subjects was measured in sitting position after 5 minutes rest, on the right arm using a mercury sphygmomanometer. The systolic and diastolic pressures were read to the nearest $2 \mathrm{mmHg}$. Systolic BP and diastolic BP were taken at phase 1 and phase 5 Korotkoff sounds respectively. The average of 3 consecutive BP readings taken at 5 minutes interval was recorded. Weight was measured using a weighing scale made by U-MEC (model 98114) with subjects wearing light clothing. Height was measured using a stadiometer to the nearest centimeter with subjects neither wearing shoes nor head gear. Body mass index $\left(\mathrm{kg} / \mathrm{m}^{2}\right)$ was calculated using the formula; Weight $(\mathrm{kg}) /$ Height $^{2}(\mathrm{~m})^{2}$.

The aetiology of renal disease in CKD subjects were determined by the researchers using the information obtained from administered questionnaires, physical examination findings and investigations in patients' clinical folders as follow:

Diabetic nephropathy: A diagnosis of diabetes mellitus, features of other microvascular complications, presence of hypertension, significant proteinuria, presence of large or normal sized kidneys on ultrasound in the absence of other possible aetiological factors.

Hypertensive nephropathy: a history of long standing hypertension, presence of features of long standing hypertension such as hypertensive retinopathy, thickened arterial wall, locomotor brachialis, loud aortic component of second heart sound.

Sickle cell nephropathy: sickle cell disease patient with or without nephrotic range proteinuria, normal sized or enlarged kidneys on ultrasound, absence of other aetiological factors like DM and hypertension.

Autosomal dominant polycystic kidney disease: presence of $\geq 3$ cysts, which may be unilateral or bilateral in patients aged between 15-39 years, $\geq 2$ cysts in each kidney for patients aged 40-59 and $\geq 4$ cysts in each kidney for patients aged $\geq 60$ and positive family history. 
Chronic glomerulonephritis: past history of acute glomerulonephritis or nephrotic syndrome, active urinary sediments, significant proteinuria, bilaterally shrunken kidneys absent features of long standing hypertension, DM or other aetiological factors.

Obstructive uropathy: presence clinical features of urinary obstruction, dilated pelvi-calyceal system, normal or enlarged kidneys on ultrasound in the absence of other aetiological factors.

About $10 \mathrm{mls}$ of fasting venous blood was obtained from patients to perform tests, which included PCV, serum CRP, albumin, creatinine and fasting serum lipids. Glomerular filtration rate (GFR) was estimated using the MDRD formula, which has been previously validated in Nigerian subjects. ${ }^{18}$

\section{C-Reactive Protein Assay}

Serum C-reactive protein was analyzed by enzymelinked immunosorbent assay (ELISA) technique. High sensitivity-CRP ELISA method is based on the principle of solid phase ELISA in which the CRP in the sample is sandwiched between immobilised monoclonal antibodies and anti-CRP antibodies in the enzyme conjugate solution. The washing off of the unbound labelled antibodies and reaction with tetramethylbenzidine (TMB) reagent lead to the development of colour, which intensity is proportional to the concentration of CRP in the sample.

Ten microliters of appropriately diluted CRP standard, samples and controls were dispensed into appropriately labeled microtitre wells (that have been brought to room temperature i.e $\left(20-25^{\circ} \mathrm{C}\right)$ after which $100 \mu 1$ of enzyme conjugate reagent was added, thoroughly mixed for 30 seconds and incubated at $20-25{ }^{0} \mathrm{C}$ for 45 minutes. The wells were later washed for 5 times with distilled water and properly dried by striking sharply on absorbent paper. $100 \mu 1$ of tetremethylbenzidine solution was then added to each well, gently mixed for 5 seconds and incubated at $20-25^{\circ} \mathrm{C}$ for 20 minutes. Thereafter, $100 \mu 1$ of $1 \mathrm{~N}$ hydrochloric acid (stop solution) was added to each well, gently mixed for 30 seconds to stop the reaction and for the development of a yellow colour, the absorbance which was read with a microtitre well reader at 450 $\mathrm{nm}$ within 15 minutes. The concentration of CRP in milligram per decilitre $(\mathrm{mg} / \mathrm{dl})$ was calculated thus:

$\mathrm{CRP}(\mathrm{mg} / \mathrm{dl})=\underline{\mathrm{A}_{\mathrm{s}}} \frac{\mathrm{X} \mathrm{\textrm {C } _ { \text { std } }}}{\mathrm{A}_{\text {std }}}$

Where; $A_{s}$ is the absorbance for the samples or controls, $\mathrm{A}_{\text {std }}$ is the absorbance for the standard and $\mathrm{C}_{\text {std }}$ is the concentration for the standard.
The assay was done in duplicates and the mean CRP calculated for each sample and control.

\section{Definition of terms}

Chronic Kidney disease has been defined as the presence of markers of kidney damage for more than 3 months with or without reduction in GFR or as the presence of GFR less than or equal to $60 \mathrm{ml} / \mathrm{min} / 1.73 \mathrm{~m}^{2}$ for 3 months with or without other signs of kidney damage. $^{19}$

CKD stage 1 (GFR $\geq 90 \mathrm{mls} / \mathrm{min}$ with evidence of kidney damage), stage 2 (GFR 60-89 $\mathrm{mls} / \mathrm{min}$ with evidence of kidney damage), stage 3 (GFR = 30-59 $\mathrm{mls} / \mathrm{min}$ with or without evidence of kidney damage), stage $4($ GFR $=15-29 \mathrm{mls} / \mathrm{min}$ with or without evidence of kidney damage) and stage 5 (GFR $<15 \mathrm{mls} / \mathrm{min}$ with or without evidence of kidney damage). ${ }^{19}$ Atherogenic index of plasma (AIP) was derived using $\log$ (TG/HDLC). ${ }^{20}$

Serum CRP levels $<1 \mathrm{mg} / \mathrm{dl}, 1-3 \mathrm{mg} / \mathrm{dl}$ and $>3 \mathrm{mg} / \mathrm{dl}$ were used to stratify the study subjects into low cardiovascular event risk, average cardiovascular event risk and high cardiovascular event risk respectively. ${ }^{14}$

\section{Data Protection}

Data were stored using Microsoft Excel program, kept secured and only released for analysis when needed. Confidentiality was maintained and the anonymity of responses ensured. Personal identifiers were not collected from participants

\section{Data Analysis}

Data generated were analysed using the statistical package for social sciences (SPSS) version 17.0. Results were presented in tabular form. Univariate analysis was used in description of demographic characteristics of the study population. Continuous variables were presented as means and standard deviation for unskewed data and median, interquartile range for skewed data. Student ttest was used to compare mean values of the CKD and control subjects for those with unskewed data while Mann Whitney U was used to compare skewed data. Discrete variables were presented as frequency and percentages. Chi-square test was used to determine the significant associations between categorical variable. Spearman's correlation was used to determine association between serum CRP and other variables while Multiple linear regression was used to determine the significant predictors of CRP. P values $<0.05$ were considered significant. 
Ethical approval was obtained from the hospital ethical committee on research and informed consent was obtained from participants.

\section{RESULTS}

This study involved $80 \mathrm{CKD}$ patients and 40 control subjects without CKD. The CKD group comprised of 53 males and 27 females. Majority of the CKD subjects were 65 years and below, accounting for $69(86.3 \%)$ of the CKD patients.

Diabetes mellitus, chronic glomerulonephritis and hypertension were the major aetiology of renal disease, accounting for $30(37.5 \%), 24(30 \%)$ and $23(28.8 \%)$ respectively.

Forty $(50 \%)$ of the CKD patients were in CKD stage 4 or 5. Fifty-one $(63.8 \%)$ of the CKD subjects had serum CRP values of $<1 \mathrm{mg} / \mathrm{L}, 13(16.2 \%)$ had value of between $1-3 \mathrm{mg} / \mathrm{L}$ while the remaining $16(20 \%)$ had values $>3 \mathrm{mg} / \mathrm{L}$ (Table 1)

Table 1 Characteristics of Study subjects (CKD patients and Control subjects)

\begin{tabular}{|c|c|c|c|}
\hline Parameter & $\begin{array}{l}\text { CKD group } \\
\mathrm{n}(\%)\end{array}$ & $\begin{array}{l}\text { Control group } \\
\mathrm{n}(\%)\end{array}$ & P value \\
\hline \multicolumn{4}{|l|}{ Gender } \\
\hline Male & $53(66.3)$ & $25(62.5)$ & 0.84 \\
\hline Female & $27(33.7)$ & $15(37.5)$ & \\
\hline \multicolumn{4}{|l|}{ Age } \\
\hline$\leq 65$ years & $69(86.3)$ & $35(87.5)$ & 0.92 \\
\hline$>65$ years & $11(13.7)$ & $5(12.5)$ & \\
\hline \multicolumn{4}{|l|}{ Diagnosis } \\
\hline Chronic glomerulonephritis & $24(30.0)$ & & \\
\hline Hypertensive nephropathy & $23(28.8)$ & & \\
\hline Diabetic nephropathy & $30(37.5)$ & & \\
\hline $\mathrm{SCN}$ & $2(2.5)$ & & \\
\hline ADPKD & $1(1.2)$ & & \\
\hline \multicolumn{4}{|l|}{ CKD stages } \\
\hline 1 & $5(6.2)$ & & \\
\hline 2 & $9(11.2)$ & & \\
\hline 3 & $26(32.5)$ & & \\
\hline 4 & $30(37.5)$ & & \\
\hline 5 & $10(12.5)$ & & \\
\hline \multicolumn{4}{|l|}{ Serum CRP values } \\
\hline$<1 \mathrm{mg} / \mathrm{L}$ & $51(63.8)$ & $38(95)$ & \\
\hline $1-3 \mathrm{mg} / \mathrm{L}$ & $13(16.2)$ & $2(5)$ & $<0.001$ \\
\hline$>3 \mathrm{mg} / \mathrm{L}$ & $16(20.0)$ & $0(0)$ & \\
\hline
\end{tabular}

cystic kidney disease),CRP (c-reactive protein)
There was no significant difference in the mean age, BMI, total cholesterol and LDL-C between the CKD and control groups. The mean systolic BP, diastolic BP, serum creatinine was significantly higher in the CKD group with $\mathrm{p}$ values of $<0.001$. The median value of serum TG, CRP and AIP were significantly higher in the CKD group with $p$ values of $<0.001$.

Table 2 Comparison of parameters between CKD and Control groups

\begin{tabular}{|c|c|c|c|}
\hline PARAMETERS & $\begin{array}{l}\text { CKD group } \\
\text { Mean } \pm \text { SD } \\
\text { /median(IQR) }\end{array}$ & $\begin{array}{l}\text { Control group } \\
\text { Mean } \pm \text { SD } \\
\text { /median(IQR) }\end{array}$ & P value \\
\hline Age (years) & $49.09 \pm 16.85$ & $45.28 \pm 15.20$ & 0.215 \\
\hline $\begin{array}{l}\text { Body mass } \\
\text { index }\left(\mathrm{kg} / \mathrm{m}^{2}\right)\end{array}$ & $24.77 \pm 4.50$ & $26.08 \pm 4.00$ & 0.15 \\
\hline $\begin{array}{l}\text { Systolic BP } \\
(\mathrm{mmHg})\end{array}$ & $160.77 \pm 28.84$ & $128.60 \pm 16.94$ & $<0.001^{*}$ \\
\hline $\begin{array}{l}\text { Diastolic BP } \\
\text { (mmHg) }\end{array}$ & $94.93 \pm 20.49$ & $81.02 \pm 10.50$ & $<0.001^{*}$ \\
\hline $\begin{array}{l}\text { Serum Creati- } \\
\text { nine (mg/dl) }\end{array}$ & $3.04 \pm 1.60$ & $0.90 \pm 0.22$ & $<0.001^{*}$ \\
\hline $\begin{array}{l}\mathrm{eGFR} \dagger \\
(\mathrm{mls} / \mathrm{min})\end{array}$ & $30.19(27.7)$ & $104.89(38.22)$ & $<0.001^{*}$ \\
\hline $\begin{array}{l}\text { Serum Albumin } \\
(\mathrm{mg} / \mathrm{l})\end{array}$ & $41.40 \pm 7.29$ & $45.41 \pm 6.96$ & $0.005^{*}$ \\
\hline $\begin{array}{l}\text { Serum CRP } \dagger \\
(\mathrm{mg} / \mathrm{dl})\end{array}$ & $0.54(2.17)$ & $0.1(0.24)$ & $<0.001 *$ \\
\hline PCV (\%) & $25.81 \pm 7.37$ & $39.16 \pm 6.12$ & $<0.001 *$ \\
\hline $\begin{array}{l}\text { Serum TC } \\
(\mathrm{mg} / \mathrm{l})\end{array}$ & $173.96 \pm 47.63$ & $179.87 \pm 42.19$ & 0.494 \\
\hline $\begin{array}{l}\text { Serum TG } \\
(\mathrm{mg} / \mathrm{l})\end{array}$ & $103(60)$ & $62.50(55)$ & $<0.001^{*}$ \\
\hline $\begin{array}{l}\text { Serum LDL-C } \dagger \\
(\mathrm{mg} / \mathrm{l})\end{array}$ & $93(43)$ & $89.65(70)$ & 0.166 \\
\hline $\begin{array}{l}\text { Serum HDL-C } \\
(\mathrm{mg} / \mathrm{l})\end{array}$ & $51.08 \pm 17.60$ & $78.82 \pm 27.88$ & $<0.001 *$ \\
\hline $\mathbf{A I P} \uparrow$ & $0.34(0.31)$ & $-0.13(0.58)$ & $<0.001 *$ \\
\hline \multicolumn{4}{|c|}{$\begin{array}{l}\text { *(Significant } p \text { value }<0.05) \dagger \text { Skewed data expressed in Median (IQR) } \\
\text { and Mann Whitney U test used. Sd(Standard deviation) IQR (Inter- } \\
\text { quartile range), eGFR (estimated glomerular filtration rate). HDL-C } \\
\text { (High density lipoprotein- cholesterol), TG (Triglyceride), TC (Total } \\
\text { cholesterol), LDL-C (low density lipoprotein cholesterol) PCV } \\
\text { (packed cell volume), BP (blood pressure), AIP (atherogenic index of } \\
\text { plasma), CRP (C-reactive protein) }\end{array}$} \\
\hline
\end{tabular}

The mean serum albumin and PCV were significantly lower in the CKD group with p-values of 0.005 and $<0.001$ respectively. The median values of serum HDL$\mathrm{C}$ and estimated GFR were significantly lower in the CKD group with $p$ values of $<0.001$ (Table 2 ).

C-reactive protein levels had significant positive correlation with BMI $(\mathrm{p}=0.004, \mathrm{r}=0.34)$, serum TG $(\mathrm{p}=$ 
$0.01, r=0.28)$, serum creatinine $(\mathrm{p}=0.02, \mathrm{r}=0.26)$ and AIP $(p=0.01, r=0.30)$. There were also significant negative correlation between CRP and serum albumin $(p=0.001, r=-0.36)$, HDL-C $(p=0.02, r=-0.26)$ and estimated GFR(p =0.01,r =0.30) (Table 3).

Table 3 Linear Correlation between CRP level and other parameters in CKD subjects

\begin{tabular}{lll}
\hline PARAMETERS & $\begin{array}{l}\mathrm{P} \\
\text { value }\end{array}$ & $\mathrm{R}$ \\
Age (years) & 0.78 & 0.03 \\
Body mass index $\left(\mathrm{Kg} / \mathrm{m}^{2}\right)$ & 0.004 & 0.34 \\
& $*$ & \\
Serum Creatinine $(\mathrm{mg} / \mathrm{dl})$ & $0.02^{*}$ & 0.26 \\
Serum Albumin $(\mathrm{mg} / \mathrm{l})$ & 0.001 & -0.36 \\
& $*$ & \\
Packed cell volume $(\%)$ & 0.58 & -0.06 \\
Serum TC $(\mathrm{mg} / \mathrm{dl})$ & 0.60 & -0.06 \\
Serum TG $(\mathrm{mg} / \mathrm{dl})$ & $0.01 *$ & 0.28 \\
Serum HDL-C (mg/dl) & $0.02^{*}$ & -0.26 \\
Serum LDL-C $(\mathrm{mg} / \mathrm{dl})$ & 0.46 & -0.08 \\
Estimated GFR $\left(\mathrm{ml} / \mathrm{min} / 1.73 \mathrm{~m}^{2}\right)$ & $0.01 *$ & -0.28 \\
AIP & $0.01 *$ & 0.30 \\
\hline
\end{tabular}

*(Significant $\mathrm{p}$ value $<0.05$ )

Glomerular filtration rate (GFR). HDL-C (High density lipoproteincholesterol), TG (Triglyceride), TC (Total cholesterol), LDL-C (low density lipoprotein cholesterol) PCV (packed cell volume), BP (blood pressure), AIP (atherogenic index of plasma), CRP (C-reactive protein), BMI(body mass index)

On multiple linear regression analysis, the significant predictors of elevated serum CRP in the CKD patients were low eGFR $(\mathrm{p}=0.03)$ and high BMI $(\mathrm{p}=0.03)$ (Table 4).

Table 4 Multiple regression analysis to determine predictors of CRP in the CKD subjects

\begin{tabular}{|l|l|l|l|l|l|}
\hline \multirow{2}{*}{ Model } & \multicolumn{2}{|l|}{$\begin{array}{l}\text { Unstandardized Coef- } \\
\text { ficients }\end{array}$} & $\begin{array}{l}\text { Standardized } \\
\text { Coefficients }\end{array}$ & & \\
\cline { 2 - 4 } & B & Std. Error & Beta & t & P-value \\
\hline 1(Constant) & 0.77 & 2.07 & & 0.37 & 0.71 \\
\hline TG & 0.01 & 0.02 & 0.20 & 0.42 & 0.68 \\
\hline HDL-C & -0.04 & 0.04 & -0.29 & -0.91 & 0.36 \\
\hline BMI & 0.12 & 0.05 & 0.26 & 2.22 & 0.03 \\
\hline AIP & -1.79 & 5.16 & -0.23 & -0.35 & 0.73 \\
\hline eGFR & -0.02 & 0.01 & -0.26 & -2.18 & 0.03 \\
\hline
\end{tabular}

eGFR (Estimated Glomerular filtration rate), HDL-C (High density lipoprotein- cholesterol), TG (Triglyceride), T, AIP (atherogenic index of plasma), CRP (C-reactive protein), BMI (body mass index)

\section{DISCUSSION}

According to the serum CRP values, 29 (36.2\%) of the CKD subjects had moderate to high cardiovascular event risk compared to only $2(5 \%)$ of the control subjects who had moderate cardiovascular event risk.

This showed that cardiovascular event risk is significantly higher in CKD subjects.

Majority of the CKD patients in this study were below 65 years of age and the common aetiologies of CKD were diabetes mellitus, chronic glomerulonephritis and hypertension which was similar to previous reports from Nigeria. ${ }^{21,22}$ Also, about 50\% of these patients had stage 4 or 5 CKD which may be due to late presentation and poor health seeking attitude of Nigerians. ${ }^{23}$

C-reactive protein has been reported to be highly valuable in predicting cardiovascular risk in CKD patients. ${ }^{11-}$ 13 Its level correlates with carotid intima media thickness in CKD patients, hence can serve as a biomarker to estimate cardiovascular risk. ${ }^{24} \mathrm{C}$-reactive protein has also been implicated as an actual promoter of atherosclerotic disease progression by binding to LDL, facilitating its deposition on the arterial wall and activating the complement system. ${ }^{25,26}$

The median serum level of hsCRP was significantly higher in the CKD group compared to the controls who did not have CKD. This suggests that the process of inflammation in CKD starts before dialysis and it is not entirely dialysis related since the CKD subjects in this study were dialysis naive. There was significant positive correlation between CRP and serum creatinine on one hand and negative correlation with estimated GFR on the other hand. Estimated GFR was also found to be a significant predictor of CRP levels in CKD in this study. This study showed that inflammation as measured by CRP level increases with declining renal function in CKD patients, similar to previous reports. ${ }^{11,13,27}$ Interventions aimed at reducing cardiovascular event risk should therefore be started as soon as a diagnosis of $\mathrm{CKD}$ is made irrespective of the stage.

C-reactive protein correlated negatively with serum albumin, a finding similar to previous studies. ${ }^{28,29} \mathrm{C}$ reactive protein and serum albumin are markers of inflammation and independent risk factors for all-cause mortality in CKD patients. ${ }^{10}$ Serum albumin may therefore serve as an alternative to CRP in assessing cardiovascular event risk in CKD patients in resource poor countries like Nigeria because of its comparatively low cost.

There was significant positive correlation between CRP and BMI in this study. Body mass index was the second significant predictor of CRP in this study. This also 
agrees with previous reports in both CKD and non-CKD subjects. $^{27,30-32}$

Visceral fat secretes pro-inflammatory cytokines that attracts macrophages that infiltrate adipocytes leading to further release of cytokines and oxygen free radicals which ultimately cause oxidative damage and atherosclerosis. $^{33-35}$

Carvalho et al in a prospective study, reported a relationship between serum CRP levels and changes in BMI and waist circumference in pre-dialysis CKD subjects. ${ }^{36}$ Weight loss was reported to reduce CRP level in both CKD and non-CKD subjects. ${ }^{32,36}$ This suggests that measures aimed at weight reduction in CKD may reduce CRP level with subsequent reduction in cardiovascular event risk.

There was also significant association between some lipid parameters and CRP level in this study. Serum CRP correlated positively with serum TG and AIP and negatively with serum HDL-C. The AIP has been reported to have higher sensitivity compared to other lipid ratios in estimating atherogenic index and predicting cardiovascular events in both CKD and non-CKD patients. $^{20,37,38}$ These associations therefore, buttress the fact that CRP is associated with increased cardiovascular event risk in CKD patients. Similar association between CRP and HDL-C has been reported in both predialysis CKD and end stage renal disease subjects who were on maintenance dialysis. ${ }^{39,40}$

This study also found an association between CRP and HDL-C. This finding is particularly important because high density lipoprotein cholesterol has both antioxidant and anti-inflammatory effects, ${ }^{41}$ hence patients with low HDL-C may have higher degree of inflammation and oxidative stress.

Therapeutic interventions and lifestyle modification aimed at treating dyslipidaemia will be valuable in reducing the level of CRP. Statins, angiotensin converting enzyme inhibitors and angiotensin receptor blockers have anti-inflammatory properties and may have additional benefits apart from their direct effects on lipids, blood pressure and proteinuria in reducing CVD morbidity and CKD progression. ${ }^{42,43}$ Some studies have also shown that statins can reduce the levels of CRP in subjects with and without CKD. ${ }^{42,44}$

The limitations of this study were the relatively small sample size and the ratio of cases to control was 2:1 due to limitation of funds because this study was selfsponsored.
Also, it was a single centre study and may not be a reflection of what pertains to other centres in Nigeria. However, this is the first study in Nigeria to determine serum CRP levels and its associated factors in predialysis CKD patients.

Recommendation: Therapeutic intervention and lifestyle modification aimed at reducing weight and treating dyslipidaemia should be instituted early in CKD patients in order to reduce associated cardiovascular risk and progression to ESRD

\section{CONCLUSION}

CKD patients have increased CRP values. Body mass index, HDL-C, TG, AIP, and eGFR are factors related to CRP levels in CKD patients.

\section{ACKNOWLEDGEMENT}

We wish to acknowledge the contributions of both the resident doctors and renal nurses of the Department of Internal Medicine towards this study.

\section{REFERENCES}

1. US Renal Data System. 2002 Annual Data Report. The National Institutes of Health, National Institute of Diabetes and Digestive and Kidney Diseases, Bethesda, MD; 2002

2. Locatelli F, Marcelli D, Conte F, D'Amico M, Del Vecchio L, Limido A et al. Cardiovascular disease in chronic renal failure: the challenge continues. Nephrol Dial Transplant 2000;15 (Suppl 5): 69-80

3. Foley RN, Parfey PS, Sarnak MJ. Clinical epidemiology of cardiovascular disease in chronic renal disease. Am J Kidney Dis 1998;339:841-843

4. Locatelli F, Marcelli D, Conte F, Del Vecchio, Limido A, Malberti F et al. Patients selection affects end stage renal disease outcome comparison. Kidney Int 2000;57 (supp1 74): 94-99.

5. Arici M, Walls J. End stage renal disease, atherosclerosis, and cardiovascular mortality: Is Creactive protein the missing link? Kidney Int 2001;59:407-417

6. Jofre R, Rodriguez-Benitez P, Lopez-Gomez J, Perez-Garcia R. Inflammatory syndrome in patients on Haemodialysis. Nephrol Dial Transpl Plus 2009;2(1):118-126

7. Muntner P, Hamm LL, Kusek JW, Chen J, Whelton PK, Jing Chen et al. The prevalence of nontraditional risk factors for coronary heart disease in patients with chronic kidney disease. Ann Intern Med. 2004; 140(1):9-17.

8. Pecoits-Filho R, Lindholm B, Stenvinkel P. The malnutrition, inflammation and atherosclerosis (MIA) syndrome-the heart of the matter. Nephrol Dial Transpl 2002:17(11);28-31 
9. De Franciso ALM, Stenvinkel P, Vaulont S. Inflammation and its impact on anaemia in CKD; from haemoglobin variability to hyporesponsiveness. Nephrol Dial Transpl Plus 2009;2(1):8-26

10. Menon V, Greene T, Wang X, Pereira AA, Marcovina S, Beck GJ et al. C-reactive protein and albumin as predictors of all-cause and cardiovascular mortality in chronic kidney disease. Kidney Int 2005; 68: 766-772

11. Annuk M, Soveri I, Zilmer M, Lind L. Endothelial function, C-reactive protein and oxidative stress in chronic kidney disease. Journal of Nephrology 1992;18(2):721-726

12. Jalal D, Chonchol M, Etgen T, Sander D. Creactive protein as a predictor of cardiovascular events in elderly patients with chronic kidney disease. J Nephrol. 2012;25(5):719-725.

13. Abraham G, Sundaram V, Sundaram V, Matthew M, Leslie N, Sathiah V. C-Reactive protein, a valuable marker in chroniv kidney disease. Saudi J Kidney Dis Transpl 2009;20(5):811-815

14. Ridker PM. Clinical Application of C-Reactive Protein for Cardiovascular Disease Detection and Prevention. Circulation 2003;107:363-369

15. Fleiss JL. Statistical methods for rates and proportions. 2nd ed. New York, NY: John Wiley\& Sons; 1981

16. Liman ML, Carvalho MG, Soares AL, Sabino AP, Fernandes AP, Novello BA et al. High-sensitivity C-reactive protein in subjects with type 2 diabetes mellitus and / or high blood pressure. Arq Bras Endocrinol Metab 2007;51(6):956-960

17. Zheni G, Margarita G, Anyla B, Mihal T, Alketa K, Myftar B et al. Inflammation and its correlation with cardiovascular risk factors in patients with chronic kidney disease. BANTAO Journal 2009;7(1):26-30

18. Sanusi AA, Akinsola A, Ajayi OO. Creatinine clearance estimation from serum creatinine values: evaluation and comparison of five prediction formulae in Nigerian patients. Afr J Med Med Sci 2000; 29:7-11.

19. KDIGO 2012 Clinical Practice Guideline of evaluation and management of CKD. Kidney Int Suppl 2013; 3(1):1-150.

20. Dobiasova M. AIP-atherogenic index of plasma as a significant predictor of cardiovascular risk: from research to practice. Vnitr Lek. 2006;52(1):64-71

21. Alebiosu CO, Ayodele OE. The global burden of chronic kidney and the way forward. Ethn Dis. 2005; 15:418-423.

22. Ulasi II, Ijoma CK. The enormity of chronic kidney disease: The situation in a teaching hospital in south-east Nigeria. Journal of Tropical Medicine Volume 2010 (2010), Article ID 501957. http://dx.doi.org/10.1155/2010/501957 accessed on the 13th October 2015

23. Chukwuezi CO, Anelechi AB. Factors associated with delay in seeking medical care among educated Nigerians. Asian Journal of Medical Science 2009; 1(2):30-32

24. Sathi S, Mahapatra H, Sunder S, Jayaraman $\mathrm{R}$, Sharma N, Verma H et al. Nontraditional cardiovascular biomarkers and estimation of cardiovascular risk in predialysis chronic kidney disease patients and their correlations with carotid intima media thickness. Nephro urol 2014;6(6):e22112. DOI:10.5812 accessed on the 13th October 2015

25. Ridker PM, Stampfer MJ, Rifai N. Novel risk factors for systemic atherosclerosis: A comparison of C-reactive protein, fibrinogen, homocysteine, lipoprotein(a), and standard cholesterol screening as predictors of peripheral arterial disease. JAMA 2001; 285: 2481-2485

26. Zwaka TP, Hombach V, Torzewski J. C-reactive protein-mediated low density lipoprotein uptake by macrophages: implications for atherosclerosis Circulation. 2001; 103(9):1194-1197

27. Pravin NB, Jayashree SB, Shilpa BA, Suhas SB, Jayashree SB, Anand PT. Study of serum uric acid and c - reactive protein levels in patients with chronic renal disease. Int J Biol Med Res. 2013; 4(1): 2758-2761

28. Razeghi E, Parkhideh S, Ahmadi F, Khashayar P. Serum CRP levels in pre-dialysis patients. Ren Fail. 2008;30(2):193-198.

29. Menon V, Wang X, Greene T, Beck GJ, Kusek JW, Marcovina SM et al.Relationship between Creactive protein, albumin and cardiovascular disease in patients with chronic kidney disease. Am J Kidney Dis 2003;42(1):44-52

30. Oboh HA, Idogun ES, Ukwuonwo AC. Assessment of high sensitivity C-reactive Protein (HSCRP) and total antioxidant status in patients with chronic kidney disease, diabetes and hypertension . JMBR 2013;12(2):105-114

31. Ramos LF, Shintani A, Ikizler TA, Himmelfarb J. Oxidative Stress and Inflammation are associated with Adiposity in Moderate to Severe CKD. Am Soc Nephrol. 2008; 19(3): 593-599

32. Tchernof A, Nolan A, Sites CK, Ades PA, PoehIman ET. Weight reduction in obese postmenopausal women. Circulation 2002;105:564-569

33. Khan NI, Naz L, Yasmeen G. Obesity: An independent risk factor for systemic oxidative stress. Pak J Pharm Sci 2006; 19: 62-65

34. Vincent HK, Taylor AG. Biomarkers and potential mechanisms of obesity-induced oxidant stress in humans. Int J Obes 2006; 30: 400-418 
35. Wellen KE, Hotamisligil GS. Obesity-induced inflammatory changes in adipose tissue. $J$ Clin Invest 2003; 112: 1785-1788

36. Carvalho LK, Barreto Silva MI, da Silva Vale B, Bregman R, Martucci RB, Carrero et al. Annual variation in body fat is associated with systemic inflammation in chronic kidney disease patients Stages 3 and 4: a longitudinal study. Nephrol. Dial. Transpl. 2012;27 (4): 1423-1428

37. Mannangi NB. Novel lipid indices in chronic kidney disease. NJMR 2015;5(1):39-42

38. Wafa FA,Elham MHJ, Zean AA. Evaluating the utility of atherogenic index of plasma among several atherogenic parameters in patients with chronic renal failure on maintenance haemodialysis. $J$ Fac Med Baghadad 2012;54(3):259-262

39. González AI, Brites F, Elbert A, Gómez-Rosso L, Berg G, Wikinski Ret al. Relation between paraoxonase activity, other HDL components and inflammatory state in hemodialyzed patients. $\mathrm{Me}$ dicina .2010;70(6):508-512

40. Bansal N, Vittinghoff E, Plantinga L, Hsu C. Does chronic kidney disease modify the association be- tween body mass index and cardiovascular risk factors. J Nephrol 2012;25(3):317-324

41. Navab M, Yu R, Gharavi N, Huang W, Ezra N, Lotfizadeh A et al. High-density lipoprotein: antioxidant and anti-inflammatory properties. Curr Atheroscler Rep 2007;9(3):244-248

42. Albert MA, Danielson E, Rifai N, Ridker PM. Effect of statin therapy on CRP levels: the pravastatin inflammation/ CRP evaluation.(PRINCE): A randomized trial and cohort study. JAMA 2001;286(1):64-70

43. Di Raimondo D, Tuttolomondo A, Butta C, Miceli S, Licata G, Pinta A. Effects of ACE-inhibitors and angiotensin receptor blockers on inflammation. Curr Pharm Des 2012;18(28):4385-4413

44. Di Lullo LE, Addesse R, Comegna C, Firmi G, Galderis C, Lannacci GR. Effects of fluvastatin treatment on lipid profile, C-reactive protein trend, and renal function in dyslipidemic patients with renal failure. Advance in Therapy 2005;22(6):601-6

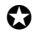

